\title{
Transgenerational Transmission of Addiction Problems
}

\author{
Amal Bernoussi, Joanic Masson, Alison Thierry, Maëlle Nicolas \\ UFR Sciences Humaineset Sociales, Chemin du Thil, 80025 Amiens Cedex, France \\ Email: joanic.masson@bbox.fr
}

Received 20 February 2015; accepted

Copyright (C) 2015 by authors and Scientific Research Publishing Inc.

This work is licensed under the Creative Commons Attribution International License (CC BY). http://creativecommons.org/licenses/by/4.0/

(c) (i) Open Access

\begin{abstract}
This paper aims to evaluate the possible transgenerational transmission of a mechanism of addiction triggered by a specific type of attachment and the prevalence of psychological trauma in the descendants. 22 adults (alcoholics, drug addicts, and heroin addicts) aged 23 to 56 followed in an addictology treatment centre are participated. Measurements: We evaluated the prevalence of family ascendants on our population using two semi structured interviews and a genogram. Potential psychological trauma was measured with the Child Trauma Questionnaire (CTQ) and the quality of attachment with the Attachment Style Questionnaire (ASQ). Findings: 95\% of patients have direct ascendants who suffer from addiction. 86\% of patients suffered emotional negligence during childhood. Physical abuse is frequent $(41 \%)$ as well as emotional abuse (50\%), which proves a form of mistreatment and explains the presence of an insecure attachment. Conclusion: Addicts have often been neglected and have lived in emotional deprivation during childhood, which is the reason for an insecure attachment. The ascendants, who often suffer from addiction themselves, have, because of their pathology, contributed to a possible transgenerational transmission of the mechanism of addiction via the quality of the affective links with their children.
\end{abstract}

\section{Keywords}

Transgenerational Transmission, Addiction, Type of Attachment, Psychological Traumas, Qualitative and Psychometric Evaluation

\section{Introduction}

We wish, through this article, to explain a recent study aiming to shed light on a possible transgenerational transmission of addictions. Our work is based on Goodman's working definition for whom addiction is "a process whereby a behaviour, which can function both to produce pleasure and to provide relief from internal discomfort, is employed in a pattern characterized by recurrent failure to control the behaviour and continuation 
of the behaviour despite significant negative consequences" ([1], p. 1404). The author defines the following criteria in order to recognize an addictive disorder:

A) Recurrent failure to resist impulses to engage in a specified behavior;

B) Increasing sense of tension immediately prior to initiating the behavior;

C) Pleasure or relief at the time of engaging in the behavior;

D) A feeling of lack of control while engaging in the behavior;

E) At least five of the followings: 1) frequent preoccupation with the behavior or with activity that is preparatory to the behavior; 2) frequent engaging in the behaviour to a greater extent or over a longer period than intended; 3) repeated efforts to reduce, control or stop the behavior; 4) a great deal of time spent in activities necessary for the behaviour, engaging in the behaviour or recovering from its effects; 5) frequent engaging in the behaviour when expected to fulfill occupational, academic, domestic or social obligations; 6) important social, occupational or recreational activities given up or reduced because of the behavior; 7) continuation of the behaviour despite knowledge of having a persistent or recurrent social, financial, psychological or physical problem that is caused or exacerbated by the behavior; 8) tolerance: need to increase the intensity or frequency of the behaviour in order to achieve the desired effect or diminished effect with continued behaviour of the same intensity; 9) restlessness or irritability if unable to engage in the behavior;

F) Some symptoms of the disturbance have persisted for at least 1 month, or have occurred repeatedly over a longer period of time.

Addictions manifest themselves by a repetition of behaviours which can trigger pleasure, but marked by dependence to a desired object or situation and eagerly used. Dependence can be triple: physical, psychological and behavioural.

Without rejecting the physiological vulnerability and socio-cultural context, misuse of psychoactive drug is usually an answer to a deep psychological suffering (inadequate self-medication). The addict tries, most often through the use of substances as well as by their behaviour, to resolve a conflict by resorting to a behaviour rather than a psychical working out and a real assimilation of what is the source of anxiety and/or depressed affect. Nevertheless, each affected person does not resort to a mechanism of addiction, which raises questions amongst the clinician-scientists of a possible organisation of personality and a possible life story likely to induce gradual addiction. We have thus asked the question of transgenerational transmission as a factor enabling a clarification of addictive aetiology. Within the framework of thisresearch, the genetic aspects under talk were not explored without being ruled out for all that by our reflexion. Deriving from the psychoanalytic paradigm, the transgenerational concept represents what is transmitted from generation to generation, what is perpetuated, more often without having been told. It is a kind of transmission of the parent's psychological experiences to their children, whether these experiences be elaborated, thoughts (family history, and myth) or unthinkable (silences, unspoken, and family secrets). What is transmitted implicitly is mainly tainted by negativity (fault, shame, repression, and non-elaborated mourning) and reflects what cannot be thought. What is unconsciously transmitted is precisely that which cannot be transmitted explicitly within the family.

The authors [2] [3] agree in differentiating two types of transmission: 1) Intergenerational transmission happens with generations in direct contact and refers to what may be said and told. The object of this transmission allows accessing a transformation process, permitting the different generations to create representations and thoughts. This type of transmission can be from the ascendant generation to the descendant, as well as from the descendant generation to the ascendant. This happens through verbal messages, gesture, and attitude. 2) Conversely, the transgenerational transmission refers more often to what can be thought, represented, and put into words. Unlike intergenerational transmission, it does not exclusively concern generations in direct contact with each other and takes into account the raw elements which cannot be represented, dreamt, or thought. The family history where those psychological heritages come from is closely linked to the secrets and the untold, and implicitly to the traumas suffered. Abraham and Torok [4] propose notions of "ghost" and "crypt" to qualify respectively the unconscious creation which is implicitly inherited and the integrated traumatic events which stay buried in the descendants' mind following transmission.

Questioning on transgenerational transmission brought us to wonder about attachment as instinctive process aiming to ensure the species' survival and to maintain proximity between mother and child [5]-[7]. This theory brings to light the importance of an early relationship between mother and baby as an essential factor to good identity building and basic security, and is vital to the good development of resilience capacities in later adulthood. In that way, through maternal care, early exploration experiences of the environment, search for prox- 
imity or absence of maternal care, the child builds him/herself and integrates a type of link which will then constitute a basis enabling bonding as an adult. Bowlby speaks of an "internal operating model" [5]. This more or less flexible model represents for the child what relationships are in general, and how to cope with others, and contributes to a representation of the world which can turn out to be secure or insecure. Depending on the quality of the relationship with the mother, Ainsworth et al. [8] identified three types of attachment: 1) The secure attachment refers to a feeling of inner safety, fruit of a containing and harmonious relationship with the mother. The child feels comfortable, in security, and can thus explore his environment whilst trusting the other. 2) The insecure anxious-avoidant attachment translates a feeling of insecurity linked to a lack of emotional support from the parents. The other is seen as little securing and the child puts in place contact avoidance strategies in order not to be deceived in general. 3) The insecure resistant-ambivalent attachment also shows such felling of insecurity. The figure of attachment is unpredictable and the child cannot find a place in his relationship with the other. The child depends on his mother and is unable to get involved with the other and his environment. Main and Solomon [9] suggest a fourth type of attachment (insecure disorganised). The child presents avoidance and ambivalence behaviours due to an attachment figure who is disorganised too, sometimes abusive, and places the child in a permanent climate of insecurity. The attachment theory resonates with Winnicott's [10] work which considers the close environment of a baby as having to be of good quality to answer physiological and emotional needs. The capacity of internal regulation of emotions, as well as the feeling of security and self-esteem, comes from the capacity of the entourage to answer the child's basic needs. Allent et al. [11] show a link between the issue of addictions and an insecure attachment. The results however only highlight a link among these issues and not causality. Insecure attachment can effectively be found in many other issues. Winnicott [12] report that an alcohol dependent lacks the introjection of the maternal function. Effectively, alcoholism is for these authors partly the result of a failure of this introjection, the person needing to fulfill the abandonic aspects through anxiolytic substance.

\section{Aims}

Addiction to substances results from a triple encounter between a product, a person with their physiological and psychological vulnerability and a socio-cultural context. Within the framework of the study presented we have focused our attention on the group the addict belongs to, their family, to answer the following general hypothesis: can the mechanism of addiction be transmitted transgenerationally, fostered by a specific type of attachment (insecure attachment) and the prevalence of traumatic events during childhood in the descendant population? In order to do so four operational hypotheses were expressed:

Operational hypothesis 1 : The persons suffering from multiple addictions have family ascendant addict themselves.

Operational hypothesis 2: The anamnesis of the persons suffering from multiple addictions reveals an accumulation of psychological traumas during childhood.

Operational hypothesis 3: The persons suffering from multiple addictions present an insecure type of attachment.

Operational hypothesis 4: We find the existence of a transgenerational transmission of the mechanism of addiction.

To evaluate such transgenerational transmission is complex and can only be concluded in an indirect way as transgenerational transmission often concerns psychological experiences more or less thought. They can nevertheless express themselves through psychological and/or behavioural symptoms. We thus opted for a causalistic and deductive reasoning in different steps: having addict parents brings to establishing an insecure type of attachment with their child, also identifiable through a traumatic experience linked to family affiliation.

\section{Method}

We opted for an approach both qualitative and psychometric in order to put to the test the hypothesis. First of all, a semi-directive interview was lead both to help creating a good quality relationship with the patients to gather information on the family and personal history. This interview aims to define the type of environment in which the person lives and their type of addiction. The items looked for are: actual situation (age, sex, socio-professsional category, family situation), the type of addiction (age of the first use, context of use, effect looked for, history with toxic substances, manifestation of addiction according to Goodman's criteria), family environment 
(quality of the relationship with the immediate family members, the parents, how was the childhood lived). The use of a genogram completed the analysis of the family functioning. This tool helps to highlight the family structure and reading its history in a transgenerational way. The genogram allows to better take into account the unconscious processes of the family such as alliances, loyalty tasks, fidelity, etc. This tool is thus essential to evaluate the existence of a transgenerational transmission of the mechanism of addiction, the semi-directive interview completing the data.

The psychotraumatic aspects of childhood were listed following the Childhood Trauma Questionnaire (CTQ, [13] [14]). This 28 items' retrospective questionnaire, in its short version, is carried out as self-evaluation and allows assessing the possible presence of 5 types of abuse occurred in childhood: physical abuse, sexual abuse, emotional abuse, emotional negligence, physical negligence.

The quality of attachment was analysed with the attachment Style Questionnaire (ASQ, [15]. This tool is preferred as the chosen population in this study consists essentially of young adults and adults. Quick and easy to use, the ASQ allows an evaluation of the different types of attachment, with reference to Ainsworth et al.'s [8] theoretical input through general social dimensions according to four profiles: autonomous attachment, preoccupied attachment, avoidant attachment, ambivalent attachment. The ambivalent attachment corresponds in the ASQ to the disorganised attachment described by Ainsworth.

Population: Our sampleiscontitued by 22 subjects. Every participant joins in a route of care in a hospital center for an addictingproblem. Some are abstinent, othersunder substitution treatment. They are lookedafter for alcoholicdependence, for drugdependency and/or for the consumption of heroin. Our group of subjectsconsists of 6 womenwhoseage varies betweet 23 and 56 years and 16 men whoseage varies between 23 and 53 years. They are coming from different socio and occupational environnent and back grounds. Our selection cuiterions is that our subjects are borderlines. The psychotic profiles as well as the foetalalcoholic syndrome were excluded from the study. Having agreed to participate, each person was asked to fill in a consent form stipulating the aims of the research, the modalities of their participation, the confidentiality of the collected data and the anonymity. Two interviews lasting around $1 \mathrm{~h} 30$ were necessary to make the assessment. The first meeting started with a semi-directive interview allowing to establish a climate of trust and to collect a minimum of information about the person. Following this, the CTQ was proposed as self-evaluation in order to bring to light any potential childhood trauma. During the second interview carried out within the two following weeks, the establishment of a genogram on two generations (parents, grand-parents) was suggested in order to collect more information about the family and point out any addiction problem for the ascendants. Finally, the second meeting was ended with an ASQ in order to evaluate the quality of attachment.

\section{Results}

Operational hypothesis 1: patients with multiple addictions have addict ascendants.

The genogram used on the 22 patients show that in $95 \%$ of patients, that is 21 out of 22 , we find a direct ascendant (parent, grand-parent) who is addict (alcohol, tobacco, psychoactive substances). The addiction often touches another family member for example an uncle or aunt.

Operational hypothesis 2: The anamnesis of patients with multiple addictions reveals an accumulation of psychological traumas during childhood.

The results obtained in the CTQ do not confirm the presence of an accumulation of traumatic experiences. However, we find recurring cases of emotional negligence ( $86 \%$ of the patients, that is 19 patients) which confirms a possible lack of emotional support for the patients. We frequently observe physical $(41 \%$ of patients, which are 9 people) and emotional abuse (50\% of patients, that is 11 people) proof of a form of mistreatment. Sexual abuse concern 3 patients in our reference group, which is approximately $13 \%$.

Operational hypothesis 3: Patients with multiple addictions present an insecure attachment type.

The ASQ highlights that all the patients who took part in the study present an insecure attachment type. More precisely, 15 people are concerned by an insecure preoccupied attachment type, 5 by an insecure avoidant type, 2 by an ambivalent insecure type.

Operational hypothesis 4: A transgenerational transmission of the mechanism of addiction is revealed.

This transmission of the addicting functioning can be perceived only from the observation, some semi-directive interview and the use of a genogram. The data show the quasi-systematic presence of unstable emotional relationships with the father or the mother, often described as distant or sometimes invasive and symbiotic. It 
should be mentioned that those parents have for the most of them had conflictual relationships with their own parents what testifies of the repetition of the problems of attachment between the generations, sogenerating a transmission of the suffering. The data analysis also shows an important level of unreported deaths, numerous family secrets or unsaid things, and often intergenerational and marital conflicts. Numerous patients explain the need to consume to better live their situation. The anxiolytic's aim is always present and constitutes an inappropriate strategy to cope.

\section{Conclusion}

While putting the results obtained into perspective owing to the small sample of subjects participating in this study, we observe that nearly all of them have a parent and/or grandparent suffering from an addiction. During this research, we focused on addictions to substances without trying to highlight any behavioural addictions. The suffering of the patient puts in danger the emotional bond with the child and seems to be transmitted to the descendants through an insecure attachment punctuated by traumatic or traumatogenic experiences, degrading the harmonious development of identity of the subjects met. It is difficult to show a direct causality between the suffering of the parent and that experienced by the child, but the clinical observations strengthen that the quality of the attachment influences the difficulty of the parent addicted to be enough packaging to his child. The observed data show both the presence of insecure attachment in the addicts and the presence of emotional negligence, proof of a lack of emotional bond and holding defect [9] from the mother. This goes Tisseron's [3] way as he highlights that an early separation felt concerning one of the parents, that addict behaviour in the family or the existence of abuse weakens a person. The met subjects resort to an addicting functioning stemming from the identification to the addict parent. The parent's suffering often translates the presence of trans-generational problems linked to the unsaid, family secrets around themes such as death or break-ups. The patients met for this research often have no idea of these events and often find themselves confronted to silence when they wish to talk about them in their family. This shows the importance both of verbally expressing what cannot be said in order to avoid spreading pain through generations, and of the need to work with addicts on everything around their traumatic experience. We have, during past studies, demonstrated the interest of approaches such as EMDR in order to promote the resolution of psychological traumas responsible for anxiety and depressive affects [16]-[18]. Working with the family can also be considered to explain what is still spectral and that way favours a reorganisation of the subjects' existence.

\section{References}

[1] Goodman, A. (1990) Addiction, Definition and Applications. British Journal of Addiction, 85, 1403-1408. http://dx.doi.org/10.1111/j.1360-0443.1990.tb01620.x

[2] Kaës, R. (1993) Le groupeet le sujet du groupe. Dunod, Paris.

[3] Tisseron, S. (2007) Transmissions et ricochets de la vie psychique entre les générations. La revue internationale de l'éducation familiale, 22, 13-26. http://dx.doi.org/10.3917/rief.022.0013

[4] Abraham, N. and Torok, M. (1978) L'écorceet le noyau. Flammarion, Paris.

[5] Bowlby, J. (1969) Attachment and Loss: Vol. 1 Attachment. Basic Books, New York.

[6] Bowlby, J. (1973) Attachment and Loss: Vol. 2 Separation: Anxiety and Anger. Basic Books, New York.

[7] Bowlby, J. (1980) Attachment and Loss: Vol. 3 Sadness and Depression. Basic Books, New York.

[8] Ainsworth, M.D.S., Blehar, M.C., Waters, E. and Wall, S. (1978) Patterns of Attachment: A Psychological Study of the Strange Situation. Erlbaum, Hillsdale.

[9] Main, M. and Solomon, J. (1986) Discovery of an Insecure Disoriented Attachment Pattern: Procedures, Findings and Implications for the Classification of Behavior. In: Brazelton, T.B. and Yogman, M.W., Eds., Affective Development in Infancy, Ablex, Norwood, 95-124.

[10] Winnicott, D.W. (1969) Les objetstransitionnels. Payot, Paris.

[11] Atger, F., Corcos, M., Perdereau, F. and Jeammet, P. (2001) Attachement et conduites addictives. Annales de Médecine Interne, 152, 1s67-1s72.

[12] Winnicott, D.W. (1975) Jeuetréalité. Gallimard, Paris.

[13] Bernstein, D.P., Fink, L., Handelsman, L., Lovejoy, M., Wenzel, K., Sapareto, E. and Gurriero, J. (1994) Initial Reliability and Validity of a New Retrospective Measure of Child Abuse and Neglect. American Journal of Psychiatry, 151, 
1132-1136.

[14] Paquette, D., Laporte, L., Bigras, M. and Zoccolillo, M. (2004) Validation de la version française du CTQ etprévalence de l'histoire de maltraitance. Santé Mentale au Québec, 29, 201-220.

[15] Feeney, J., Noller, P. and Hanrahan, R. (1994) Assessing Adult Attachment. In: Berman, W. and Sperling, M., Eds., Attachment in Adults: Clinical and Developmental Perspectives, Guilford Press, New York, 128-151.

[16] Masson, J. (2005) L'outil EMDR en alcoologie: Réflexions théoriques et cliniques. Psychothérapies, 25, 117-123. http://dx.doi.org/10.3917/psys.052.0117

[17] Brennstuhl, M.J., Tarquinio, C., Montel, S., Masson, J., Bassan, F. and Tarquinio, P. Utilisation de la thérapie EMDR pour le traitement du syndrome du sein fantôme: Etude de cas. Sexologie, in Press.

[18] Bernoussi, A. and Masson, J. (2014) Toward a somatic resilience? In: Ionescu, S, Ed., The Second World Congress on Resilience: From Person to Society, Monduzzi Editore, Bologne, 1123-1129. 